\title{
LONG ASHTON RESEARCH STATION, BRISTOL
}

$\mathrm{T}$

HE staff of the University of Bristol Agricultural and Horticultural Station at Long Ashton includes 47 graduate scientific officers and now totals 225 , approximately double the pre-war figure. The basic work of the Station on all aspects of fruit culture and fruit utilization has similarly expanded, and there has been, in addition, a rapid growth in biochemical studies related to plant nutrition, a development stimulated by the formation in 1952 of the Agricultural Research Council Unit of Plant Nutrition (Micronutrients), the members of which were assimilated into the Long Ashton staff in 1959.

These increases in staff and research programmes have necessitated new laboratories and ancillary services. A comprehensive building scheme for the Station was drawn up in 1949, and, although the proposed plans have not all been implemented, a substantial instalment of the programme has now been completed. On July 6, Sir William Slater, formerly secretary of the Agricultural Research Council, declared open the buildings that have been constructed during the past five years. Of these, the three principal are : (1) a range of experimental glasshouses with attached laboratories and special- purpose rooms; (2) a refectory/common room adaptable for use as a hall for lectures and meetings; (3) the Wallace Laboratory, named after Prof. T. Wallace who retired from the directorship in 1957 after having served the Station for thirty-eight years. The Glasshouse/Laboratory block, a building of 43,000 sq. ft., has six separate glasshouses, each $72 \times 34 \mathrm{ft}$. with a ridge-height of $24 \mathrm{ft}$., constructed of a suspended 'Aluminex' framework with side walls infilled with 2 -ft. brickwork. The houses, from west to east, are used respectively for propagation, plant nutrition (two houses), pomology, plant pathology and entomology. Each glasshouse communicates by a short corridor to a header house $220 \times 18 \mathrm{ft}$. The southern half of the header house, adjacent to the glasshouses, forms an open gallery; the northern half is divided to form laboratories, stores, cold rooms and special-purpose rooms with controlled environment. A set of rooms for work on radioactive tracers is segregated at the east end of the header house; the west end houses the services for soil and plant preparation.

The main boiler house, attached at the west of the glasshouse block, contains three oil-fired automatic-

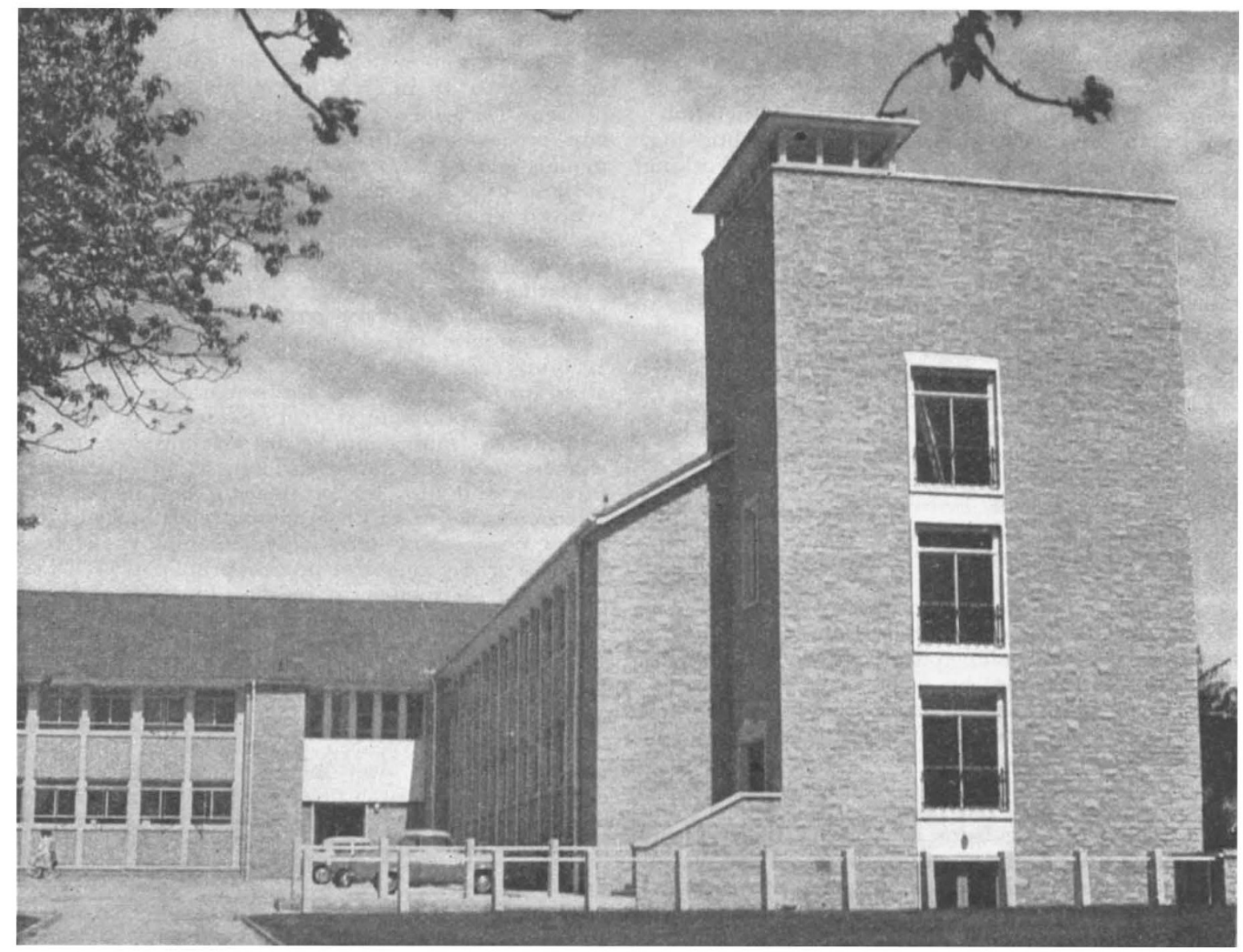

Fig. 1. The Wallace Laboratory of Long Ashton Research Station 
ally controlled McNiel boilers, providing space heating and hot water for the glasshouses, the refectory and the Wallace Laboratory. Steam conveyed through underground conduits supplies heat exchangers for the production of hot water, which is passed through radiators, ceiling coils or hot-air circulators.

The Refectory/Common Room is a single-storyed building covering 5,300 sq. ft. It is faced with 'Reformite' reconstructed stone and has large french windows overlooking a pleasant expanse of the fruit plantations. The roof is of double-Roman tiles and the floor of polished Iroko wood blocks. The dining hall, $60 \times 37 \mathrm{ft}$., connects through a folding partition to the common room $35 \times 37 \mathrm{ft}$. With the partition open a hall $95 \times 37 \times 20 \mathrm{ft}$. high is provided. There is a well-appointed kitchen equipped with air extractors and refrigerated larder. The building is heated by a hot-air circulatory system linked to the main boiler house.

The Wallace Laboratory is a two-storyed, T-shaped building of 24,000 sq. $\mathrm{ft}$. floor space, roofed and the walls faced in the same style as the refectory (Fig. 1). The entrance hall is panelled in apple-wood veneer cut from a tree of the cider variety 'Knotted Kernel' which formerly stood on the site. Some of its sister trees of the original cider orchard (planted in 1904) still flourish around the new laboratory. The western arm of the building houses the administration section on the ground-floor, and laboratories for analytical chemistry above. The southern limb of the ground-floor accommodates the pomology and plantations sections, with stores and organic chemistry on the first floor. The remainder of the ground. floor has laboratories for physical chemistry, statistics and willow research, with the section for nutrition of fruit plants above. There are extensive basement rooms for stores and heat-exchange equipment, with a tower at the southern end housing the water cisterns and capped by an observation platform for meteorological recording. The lofts house elaborate fume extractors and 'Plenum' heating equipment.

Among other buildings is one of $8,400 \mathrm{sq}$. ft. consisting of laboratories for biochemistry and plant physiology which was completed in 1956. During 1959-60, the director's room, the committee room and the library in the Barker Laboratory (the original laboratory building) were redecorated and re-furnished. Extensive improvements and additions have also been made to workshops, machinery sheds and roadways.

\section{THE BRITISH IRON AND STEEL RESEARCH ASSOCIATION}

$\mathrm{T}$ HE Sheffield Station of the British Iron and Steel Research Association, where open days were held on June 15 and 16, houses three of the Association's five main research divisions-the Steelmaking, Metallurgy (General), and Mechanical Working Divisions.

\section{Steelmaking}

The Steelmaking Division is responsible for research into all the modern processes involved in the conversion of iron into steel, and prominent among its present research projects are the control of electricarc and open-hearth furnaces, continuous casting, and the use of oxygen in steelmaking operations.

The use of large electric-arc furnaces for the bulk production of steel is increasing and it is expected that, in 1965, these furnaces will account for one million tons more of Britain's total annual steel output than in 1960. Economy in the use of electrical power is becoming, therefore, a matter of increasing importance. The automatic power input controller (Apic), which has been developed recently by the Steelmaking Division for application to electric-arc furnaces, has already shown itself capable of achieving significant reductions in electricity consumption. Trials have been carried out satisfactorily on the Association's experimental furnace at Sheffield and on a 5-ton production furnace at Steel, Peech and Tozer, and further trials are now being carried out on another member's 30-ton furnace.

Continuous casting helps to achieve higher yields and greater uniformity of end product. A number of continuous casting plants has recently been installed or projected, including a twin-strand plant at the Abbey Works of the Steel Co. of Wales. This is based on the process developed by the Association in conjunction with the Continuous Casting $\mathrm{Co}$. of
Weybridge, and will be used for casting low-carbon slabs up to 48 in. $\times 8$ in. in section. The Steelmaking Division's present investigations into this new process are directed mainly towards improved moulds and mould reciprocating cycles. Arising out of these investigations, a new design of mould has been evolved which enables three interconnected ingots to be cast simultaneously, these being afterwards separated and treated as individual castings.

During the past fow years there has been a dramatic increase in the use of oxygen for steelmaking processes and the new vessels now being introduced into Britain, such as the L.D., Kaldo and Rotor, will alone probably account for something like 14 per cent of the total annual steel production in 1965. In addition to pure refining duties, however, oxygen can be used for flame enrichment in open-hearth furnaces and also for pretreating hot metal. The Division is at present conducting trials of a new hotmetal pre-treating device which employs a simple reversal of the converter process principle. With this technique-termed spray refining-instead of passing oxidizing gases through molten metal, the metal is teemed through jets of oxidizing gas, thus breaking up the falling stream of metiol and-by increasing the effective metal surface area-promoting rapid and efficient refining reactions.

The current research programme of the Steelmaking Division also includes investigations into control of open-hearth furnace combustion, the rapid desulphurization of electric steel and studies of subcutaneous segregates.

\section{Metallurgy}

The Metallurgy (General) Division is concerned with the physical, chemical and mechanical properties of iron and steel, and the effect on these properties 